\title{
Design and Development of Clamping Fixture for Drilling of Boiler Tube Plate
}

\author{
Sunny N. Shahane*, Amol D. Lokhande, Sanjivani R. Bhosale, Amit V. Patil, Neha S. Shirodkar \\ Savitribai Phule Pune University, MIT College of Engineering, Pune, India
}

Accepted 02 March 2016, Available online 15 March 2016, Special Issue-4 (March 2016)

\begin{abstract}
Present invention provides special design of clamping fixture for drilling of boiler tube plate. This clamping fixture is necessary in order to self centre the boiler tube plate. This self-centering can be done by using rack and pinion mechanism. This fixture was designed and built to hold, support and locate fire tube boiler plate to ensure that it is drilled with accuracy. The fixture set up for component is done manually. For that more cycle time required for loading and unloading the material so, there was a need to develop a system which can help in improving productivity and time. Fixtures reduce operation time and increase productivity and high quality of operation is possible.
\end{abstract}

Keywords: Clamping fixture, Self Centering, Rack and Pinion, Hydraulic Clampers, Simulation in solid works, etc.

\section{Introduction}

The present scenario is that for the purpose of drilling of fire tube boiler plate manual clamping method is used. This consumes more time and due to which production rate affects. Hence clamping and declamping requires high manpower. Also during drilling vibrations are induced to remove that the conventional method of setting blocks is used. These blocks may obstruct the path of tool and require constant relocating of the blocks. Fixture design plays an important role at the setup planning phase. Proper fixture design is crucial for developing product quality in different terms of accuracy, surface finish and precision of the machined parts. In existing design the fixture set up is done manually, so the aim of this project is to replace with hydraulic fixture to save time for loading and unloading of component. Hydraulic fixture provides the manufacturer for flexibility in holding forces and to optimize design for machine operation as well as process functionability.

\subsection{Steps for Fixture Design}

Successful fixture designs begin with a logical and systematic plan. With a complete analysis of the fixture's functional requirements, very few design problems occur. The following is a detailed analysis of each step.

Step 1: Define Requirements
Step 2: Collect/Analyze Information

Step 3: Develop Several Options

Step 4: Choose the Best Option

Step 5: Implement the Design

\subsection{Consideration Parameters}

Designing of fixtures depends upon so many factors. These factors are analyzed to get design inputs for fixtures. The list of such factors are mentioned below:

1) Study of work piece and finished component size and geometry.

2) Type and capacity of the machine, its extent of automation.

3) Provision of locating devices in the machine.

4) Available clamping arrangements in the machine.

5) Available indexing devices, their accuracy.

6) Evaluation of variability in the performance results of the machine.

7) Rigidity and of the machine tool under consideration.

8) Study of ejecting devices, safety devices, etc.

9) Required level of the accuracy in the work and quality to be produced

\subsection{Fixture Design}

To meet all design criteria for work holder is impossible, compromise is inevitable. The most important hint of optimal design objectives is positioning, holding\& supporting functions that fixtures must fulfill. 


\section{1) Position:}

fixture must above all else hold the work piece, precisely in place to prevent 12 degrees of freedom, linear movement in the either direction about each axis.

2) Repeatability:

Identical work piece specimens should be located by work holder in precisely the same space on repeated loading \& unloading cycles. It should be impossible to hold the work piece incorrectly.

3) Adequate clamping forces:

The work holder must hold the work piece immobile against the forces of gravity. Centrifugal force, inertia force, wetting force, milling \& the design must calculate these machines forces against the fixture holding capacity. The device must be rigid: clamping forces must be maintained.

4) Care during loading cycles:

As the work holders usually receive more punishment during the loading \& unloading cycle than during the machining operation. The device must endure impact \& aberration for at least the life of the job.

\subsection{Literature Survey}

Shailesh S. Pachbhai, Laukik P. Raut etal. (2014) have described that in machining fixtures, minimizing work piece deformation due to clamping and cutting forces is essential to maintain the machining accuracy. This can be achieved by selecting the optimal location of fixturing elements such as locators and clamps. The fixture set up for component is done manually. For that more cycle time required for loading and unloading the material. So, there is need to develop system which can help in improving productivity and time.

T. Papastathisa, O. Bakkera, S. Ratcheva, A. Popova etal. (2012) have described that instead of using passive fixture element use active fixture element because it reduce the dynamic deformation of the work piece by $84.2 \%$.

Chetankumar M. Patel, Dr. G. D. Acharya, etal. (2014) have discussed that Paper proves utility of hydraulics in fixture design in three different ways: (i) reduces cycle time, (ii) reduces operator fatigue and increases productivity and (iii) reduces wear and tear of fixture components.

\section{Centering of Tube Plate}

Initially centering of the plate is done manually. Perpendicular diameters are drawn approximately and center is plotted. Now the plate is loosely clamped and tool is allowed to move from one end point of diameter towards the other and then the tool moves half of the distance backward to obtain the center. If this center matches with the manually obtained center then machining is done by tightening the clamping or else procedure is repeated unless and until exact center is obtained. During the drilling operation vibrations are induced in the plate. Hence to overcome this presently $100 * 100 \mathrm{~mm}$ blocks are placed below plate to support it.

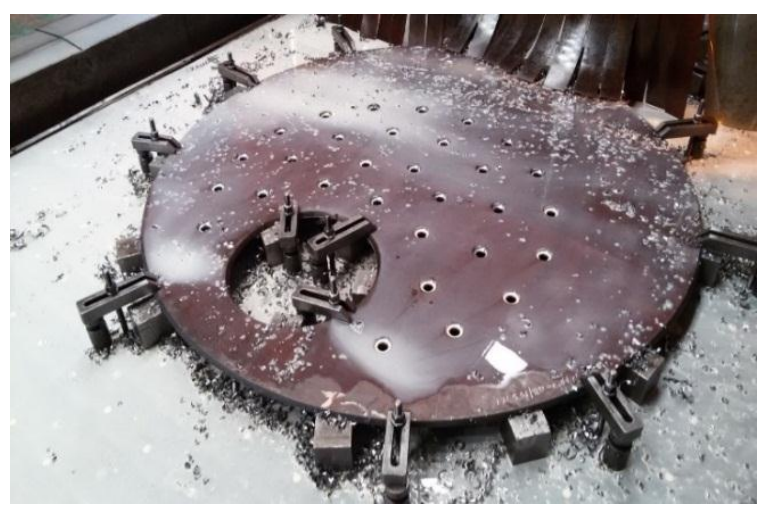

Fig 1. Actual Mounting of Plate

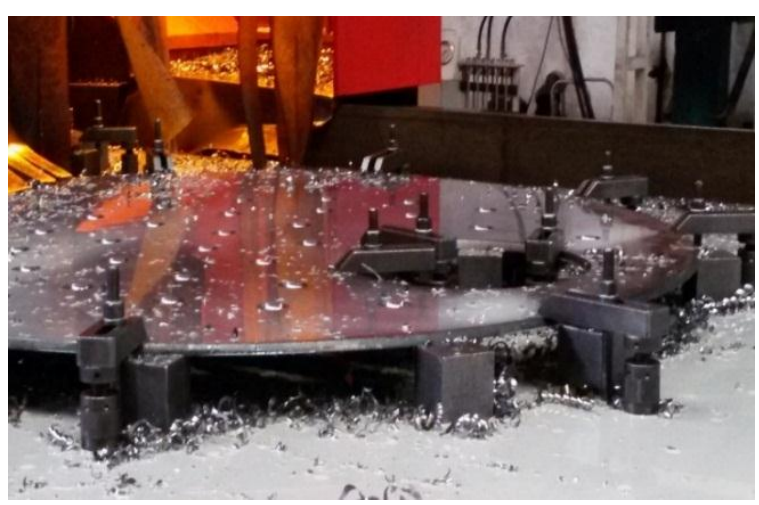

Fig 2. Manually adjusted Clamps

\section{Major Parts of the System}

The following major parts are used in this system

1) Rack and Pinion

2) Shaft

3) Bearing

4) Coupling

5) Stand

6) Base plate

7) Clampers

\section{Design Procedure}

\subsection{Design of Rack and Pinion}

We have the standard rack and pinion pair available from ATALANTA RACK AND PINION Company.

Selection criteria are as follow:

Force required to pull the plate $=$ weight of $2 \mathrm{~m}$ diameter plate

$$
\begin{aligned}
& \mathrm{W}=\text { volume } \times \text { density } \times 9.81 \\
& \mathrm{~W}=\pi r^{2} \times 7850 \times 9.81=5320
\end{aligned}
$$


Step 1: Determining the Tangential Force

$$
\begin{aligned}
\mathrm{a} & =\frac{\mathrm{v}}{\mathrm{t}}\left[\mathrm{m} / \mathrm{s}^{2}\right] \\
\mathrm{F} & =((\mathrm{m} \times \mathrm{g} \times \mu)+(\mathrm{m} \times \mathrm{a})) \mathrm{N}
\end{aligned}
$$

Step 2: From the given force select the standard rack and pinion pair and calculate Fperm.

$$
\mathrm{F}_{\text {perm. }}=\frac{\mathrm{F}(\mathrm{tab})}{\mathrm{KA} \cdot \mathrm{SB} \cdot \mathrm{fn} \cdot \mathrm{LKHB}}
$$

The Condition $\mathbf{F}<\mathbf{F}$ perm. Must be fulfilled. Step 3: Selection of load Factor $\mathrm{K}_{\mathrm{A}}$ :

Table 1. Shock Load Factor

\begin{tabular}{|c|c|c|c|}
\hline Drive & \multicolumn{3}{|c|}{ Type of load from the machines to be } \\
driven
\end{tabular}

Step 4: Safety Coefficient $\mathrm{S}_{\mathrm{B}}$ :

The safety coefficient should be taken as 1.1 to 1.4 (SB $=1.1$ to 1.4$)$.

Step 5: Life-Time Factor (fn):

Considering the peripheral speed of the pinion and lubrication.

Table 2. Life time factor

\begin{tabular}{|c|c|c|c|}
\hline $\begin{array}{c}\text { Lubrication } \\
\text { Peripheral Speed } \\
\text { of Gearing m/sec }\end{array}$ & Continuous & Daily & Monthly \\
\hline 0.5 & 0.85 & 0.95 & \multirow{1}{*}{} \\
\hline 1.0 & 0.95 & 1.10 & \\
\hline 1.5 & 1.00 & 1.20 & \multirow{2}{*}{3 to 10} \\
\hline 2.0 & 1.05 & 1.30 & \\
\hline 3.0 & 1.10 & 1.50 & \multirow{2}{*}{} \\
\hline 5.0 & 1.25 & 1.90 & \\
\hline
\end{tabular}

Step 6: Selection of Linear Load Distribution Factor LKHB:

The linear load distribution factor considers the contact stress, while it describes unintegrated load distribution over the tooth width. Supporter.

$\mathrm{L}_{\mathrm{KHB}}=1.1$ for counter bearing, e.g. Torque

$=1.2$ for preloaded bearings on the output shaft e.g. ATLANTA HT, HP and E servo-worm gear unit, BG bevel-gear unit.

$=1.5$ for un-preloaded bearings on the output shaft e.g. ATLANTA B servo-worm gear unit.

Calculations:

Mass to be Moved $(\mathrm{m})=550 \mathrm{~kg}$

Speed $(\mathrm{v})=0.05 \mathrm{~m} / \mathrm{s}$
Acceleration Time $\left(t_{b}\right)=1 \mathrm{~s}$

Acceleration Due to Gravity $(\mathrm{g})=9.81 \mathrm{~m} / \mathrm{s}^{2}$

Coefficient of Friction $(\mu)=0.23$

Load Factor $\left(\mathrm{K}_{\mathrm{a}}\right)=1.25$

Life-Time Factor $\left(\mathrm{f}_{\mathrm{n}}\right)=0.85$

Safety Coefficient $\left(\mathrm{S}_{\mathrm{B}}\right)=1.4$

Linear Load Distribution Factor $\left(\mathrm{L}_{\mathrm{KHB}}\right)=1.5$

$\mathrm{a}=\frac{\mathrm{v}}{\mathrm{t}}=0.05 \mathrm{~m} / \mathrm{s}^{2}$

$\mathrm{Fu}=((\mathrm{m} \times \mathrm{g} \times \mu)+(\mathrm{m} \times \mathrm{a}))$

$\mathrm{Fu}=((550 \times 9.81 \times 0.23)+(550 \times 0.05))$

$\mathrm{Fu}=1.268 \mathrm{KN}$

Assumed feed force:

Rack C45, ind. hardened, straight tooth, module 3.

Pinion $16 \mathrm{MnCr} 5$, case hardened, 40 teeth,

with $\mathrm{F}_{\mathrm{tab}}=16.5 \mathrm{KN}$

$\begin{aligned} F_{\text {perm. }} & =\frac{\mathrm{F}(\mathrm{tab})}{\mathrm{Ka} \cdot \mathrm{SB} \cdot \mathrm{fn} \cdot \mathrm{LKHB}} \\ \mathrm{F}_{\text {perm. }}= & \frac{16.5}{1.25 \times 1.4 \times 0.85 \times 1.5}\end{aligned}$

$\mathrm{F}_{\text {perm. }}=7.39 \mathrm{KN}$

Condition

$\mathrm{F}_{\text {perm }}>\mathrm{F}_{\mathrm{u}}$;

$1.268 \mathrm{KN}>7.39 \mathrm{KN}=>$ fulfilled

Result:

Rack 27301001

Pinion 2435240 (case hardened).

\subsection{Design of Shaft}

The shaft is designed using ASME code. According to this code, the permissible shear stress $T_{\max }$ for the shaft without keyways is taken as $30 \%$ of yield strength in tension or $18 \%$ of the ultimate tensile strength of the material, whichever is minimum. If keyways are present, the above are reduced by $25 \%$. Also, the bending and torsional moments are to be multiplied by factors $K_{b}$ and $K_{t}$ respectively, to account for shock and fatigue.

Thus,

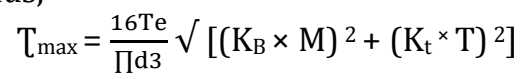

Where,

$\mathrm{K}_{\mathrm{b}}=$ combined shock and fatigue factor applied to bending moment

$\mathrm{K}_{\mathrm{t}}=$ combined shock and fatigue factor applied to torsional moment

Step 1: Selection of material for shaft

The material selected for the shaft is C40 [7]

The values of the ultimate tensile strength and yield strength are as follows:

$\mathrm{S}_{\mathrm{ut}}=640 \mathrm{~N} / \mathrm{mm}^{2}$

$\mathrm{S}_{\mathrm{yt}}=380 \mathrm{~N} / \mathrm{mm}^{2}$

Step 2: Calculation of permissible shear stress

Allowable stress $=.75 \times .3 \times \mathrm{S}_{\mathrm{yt}}$ or $.75 \times .18 \times \mathrm{S}_{\mathrm{ut}}$ $=85.5 \mathrm{~N} / \mathrm{mm}^{2}$ or $86.4 \mathrm{~N} / \mathrm{mm}^{2}$ 
Hence, permissible shear stress is $85.5 \mathrm{~N} / \mathrm{mm}^{2} \quad \ldots$ Minimum value is taken.

Step 3: Calculation for maximum bending moment Force acting on pinion is $\mathrm{F}=1.25 \mathrm{KN}$

This force is resolved into two components as follows:

1. Tangential component acting in the direction of motion of pinion.

$$
\begin{aligned}
& \mathrm{F}_{\mathrm{t}}=\mathrm{F} \cos (\alpha) \\
& =1.25 \times \cos (20) \\
& \text { of pinion } \\
& =1.17 \mathrm{KN}
\end{aligned}
$$

.... $20^{0}$ pressure angle

2. Radial component acting away from the centre of the pinion.

$$
\begin{aligned}
\mathrm{F}_{\mathrm{r}} & =\mathrm{F}_{\mathrm{t}} \tan (\alpha) \\
& =1.17 \times \tan (\alpha) \\
& =0.427 \mathrm{KN}
\end{aligned}
$$

Vertical force diagram

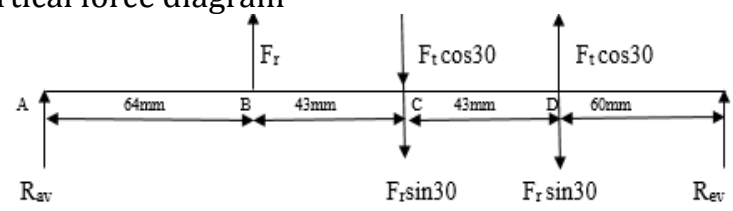

$\sum \mathrm{F}_{\mathrm{y}}=0$

Therefore, from vertical force diagram,

$F_{r}-F_{r} \sin 30-F_{r} \sin 30+F_{t} \cos 30-F_{t} \cos 30+R_{A V}$ $+\mathrm{R}_{\mathrm{EV}}=0$

$0.427-2 \times(0.427) \times \sin 30+R_{A V}+R_{E V}=0$

$\mathrm{R}_{\mathrm{AV}}+\mathrm{R}_{\mathrm{EV}}=0$.... (1)

Consider the moments about ' $\mathrm{A}$ '.

$\sum \mathrm{M}_{\mathrm{a}}=0$

$\mathrm{F}_{\mathrm{r}} \times 64-\left(\mathrm{Ftcos} 30+\mathrm{F}_{\mathrm{r}} \sin 30\right) \times 107+\left(\mathrm{Ft} \cos 30-\mathrm{F}_{\mathrm{r}} \sin 30\right) \times$

$150+R_{E V} \times 210=0$

Thus,

$\mathrm{R}_{\mathrm{EV}}=-0.076 \mathrm{KN}$

$\mathrm{R}_{\mathrm{AV}}=0.076 \mathrm{KN}$ follows:

Bending moments at different points are as

$$
\begin{aligned}
\mathrm{M}_{\mathrm{BV}} & =\mathrm{R}_{\mathrm{AV}} \times 64 \\
& =4.864 \mathrm{KN}-\mathrm{mm} \\
\mathrm{M}_{\mathrm{CV}} & =\mathrm{R}_{\mathrm{AV}} \times 107+\mathrm{F}_{\mathrm{r}} \times 43 \\
& =26.514 \mathrm{KN}-\mathrm{mm} \\
\mathrm{M}_{\mathrm{DV}} & =\mathrm{R}_{\mathrm{EV}} \times 60 \\
& =-4.595 \mathrm{KN}-\mathrm{mm}
\end{aligned}
$$

Horizontal force diagram

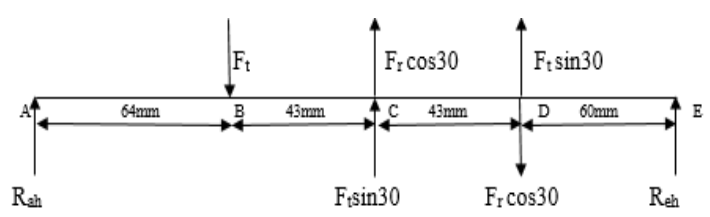

$\sum \mathrm{F}_{\mathrm{y}}=0$

Therefore, from horizontal force diagram,
$-1.17-2 \times(1.17) \times \sin 30+R_{A H}+R_{E H}=0$

$\mathrm{R}_{\mathrm{AH}}+\mathrm{R}_{\mathrm{EH}}=0$.... (1)

Consider the moments about 'A'.

$\sum \mathrm{M}_{\mathrm{a}}=0$

$-F_{t} \times 64+\left(F r \cos 30+F_{t} \sin 30\right) \times 107+\left(F t \sin 30-F_{r} \cos 30\right) \times$ $150+\mathrm{R}_{\mathrm{EH}} \times 210=0$

Thus,

$\mathrm{R}_{\mathrm{EH}}=-0.28 \mathrm{KN}$

$\mathrm{R}_{\mathrm{AH}}=0.28 \mathrm{KN}$ follows:

Bending moments at different points are as

$\mathrm{M}_{\mathrm{BH}}=\mathrm{R}_{\mathrm{AH}} \times 64$

$$
=17.92 \mathrm{KN}-\mathrm{mm}
$$

$\mathrm{M}_{\mathrm{CH}}=\mathrm{R}_{\mathrm{AH}} \times 107-\mathrm{F}_{\mathrm{t}} \times 43$

$=-20.35 \mathrm{KN}-\mathrm{mm}$

$\mathrm{M}_{\mathrm{DH}}=\mathrm{R}_{\mathrm{EH}} \times 60$

$=-16.8 \mathrm{KN}-\mathrm{mm}$

Resultant bending moments

$$
\begin{aligned}
\mathrm{M}_{\mathrm{B}} & =\sqrt{ }\left[\left(\mathrm{M}_{\mathrm{BH}}\right)^{2}+\left(\mathrm{M}_{\mathrm{BV}}\right)^{2]}\right. \\
& =1.856 \mathrm{KN}-\mathrm{mm} \\
\mathrm{M}_{\mathrm{C}} & =\sqrt{ }\left[\left(\mathrm{M}_{\mathrm{CH}}\right)^{2}+\left(\mathrm{M}_{\mathrm{CV}}\right)^{2]}\right. \\
& =33.42 \mathrm{KN}-\mathrm{mm} \\
\mathrm{M}_{\mathrm{D}} & =\sqrt{ }\left[\left(\mathrm{M}_{\mathrm{DH}}\right)^{2}+\left(\mathrm{M}_{\mathrm{DV}}\right)^{2]}\right. \\
& =17.41 \mathrm{KN}-\mathrm{mm}
\end{aligned}
$$

Therefore the highest total bending moment is occurring at point ' $\mathrm{C}$ '.

Hence $\mathrm{M}=33.42 \mathrm{KN}-\mathrm{mm}$

Step 4: Calculation of torsional moment

Torque acting on the shaft is

$\mathrm{T}=\mathrm{F}_{\mathrm{t}} \times \mathrm{r}$

$$
=0.0702 \times 10^{3} \mathrm{KN}-\mathrm{mm}
$$

Step 5: Calculation of equivalent torsional moment For gradually loaded rotating shaft $\mathrm{K}_{\mathrm{b}}=1.5$ and $\mathrm{K}_{\mathrm{t}}=1 \quad$.... V. B. Bhandari Pg. No.334 Thus the equivalent torque is $\mathrm{Te}=\sqrt{ }\left[\left(\mathrm{K}_{\mathrm{B}} \times \mathrm{M}\right)^{2}+\left(\mathrm{K}_{\mathrm{t}} \times \mathrm{T}\right)^{2}\right]$ $=86.26 \mathrm{KN}-\mathrm{mm}$

Step 6: Verification of safety of shaft

The allowable torsional stress is given as $\mathrm{T}_{\text {all }}=\frac{16 \mathrm{Te}}{\Pi \mathrm{d} 3}$

$$
=10.24 \mathrm{~N} / \mathrm{mm}^{2}>85.5
$$

Therefore design is safe.

\subsection{Design of key}

Step 1: Selection of material

C50 is selected as material for key

$\mathrm{S}_{\mathrm{ut}}=520 \mathrm{~N} / \mathrm{mm}^{2}$

$\mathrm{S}_{\mathrm{yt}}=340 \mathrm{~N} / \mathrm{mm}^{2}$

Step 2: Determination of dimensions of the key

For diameter of $35 \mathrm{~mm}$, the dimensions of keys are $10 \mathrm{~mm} \times 8 \mathrm{~mm}$.

Step 3: Permissible compressive and shear stresses 


$$
\begin{aligned}
\sigma_{\mathrm{c}} & =\frac{s y c}{f s} \\
& =340 / 3 \\
& =113.33 \mathrm{~N} / \mathrm{mm}^{2}
\end{aligned}
$$

According to maximum shear stress theory of failure,

$$
\begin{aligned}
\mathrm{S}_{\mathrm{sy}} & =0.5 \mathrm{~S}_{\mathrm{yt}} \\
& =0.5 \times 340 \\
& =170 \mathrm{~N} / \mathrm{mm}^{2} \\
\mathrm{~T} & =\frac{\text { Ssy }}{f s} \\
& =170 / 3 \\
& =56.67 \mathrm{~N} / \mathrm{mm}^{2}
\end{aligned}
$$

Step 4: Determination of induced compressive and shear stress

$$
\begin{aligned}
\sigma_{\mathrm{c}} & =\frac{4 * T}{d * h * l} \\
& =\frac{4 * 70.2 * 1000}{35 * 8 * 30} \\
& =33.42 \mathrm{~N} / \mathrm{mm}^{2}<113.33 \mathrm{~N} / \mathrm{mm}^{2} \\
\mathrm{~T} & =\frac{2 * T}{d * b * l} \\
& =\frac{2 * 70.2 * 1000}{35 * 10 * 30} \\
& =13.37 \mathrm{~N} / \mathrm{mm}^{2}<56.67 \mathrm{~N} / \mathrm{mm}^{2}
\end{aligned}
$$

Hence, the design of key is safe.

\subsection{Design of Bearings}

Procedure for selection of bearing from manufacturing catalogue

Step 1:

Calculate i) radial $\left(f_{r}\right)$ and axial forces $\left(f_{a}\right)$ acting on the bearings
ii) Diameter of shaft (d)
iii) Speed of shaft (n)

Step 2:

Select the type of bearing for the given application. Step 3:

Calculate the values of $\mathrm{X}$ and $\mathrm{Y}$, the radial and thrust factors, from the catalogue. These values depends upon ratios, $\left(\mathrm{f}_{\mathrm{a}} / \mathrm{f}_{\mathrm{r}}\right)$ and $\left(\mathrm{f}_{\mathrm{a}} / \mathrm{C}_{0}\right)$. The selection therefore, done by trial and error method.

To begin with, a bearing of light series, such as 60 ,is selected for the given diameter of the shaft and the values of $\mathrm{C}_{0}$ is found from the catalogue.

Step 4:

Calculate the equivalent dynamic load from the equation.

$$
P=X \times f_{r}+Y \times f_{a}
$$

\section{Step 5.}

Make a decision about the expected bearing life and express the life $\mathrm{L}_{10}$ in million revolutions.

$$
\begin{aligned}
\mathrm{L}_{10} & =\frac{60 \times \mathrm{n} \times \mathrm{L}_{10 \mathrm{~h}}}{10^{6}} \\
\mathrm{~L}_{10} & =\frac{60 \times 10 \times 30000}{10^{6}} \\
& =18 \text { millions } \\
\text { Step 6: } & \\
\mathrm{C} & =\mathrm{P} \times\left(\mathrm{L}_{10}\right)^{1 / \mathrm{a}} \\
\mathrm{a} & =3(\text { ball bearing) } \\
\mathrm{C} & =360.49 \times(18)^{1 / 3}
\end{aligned}
$$

$$
\begin{aligned}
& \quad=944.7525 \mathrm{~N} \\
& \mathrm{C}_{\mathrm{r}}=19613.3 \\
& \text { So, } \mathrm{C}_{\mathrm{r}}>\mathrm{C} \\
& \text { So selected bearing is safe }
\end{aligned}
$$

Step 7: Referring the SKF manufacturing catalogue the selected bearing no is 6207[6]

Dimensions of the bearing:-

Inner diameter of shaft $=35 \mathrm{~mm}$

Outer diameter of shaft $=72 \mathrm{~mm}$

Thickness of bearing $=17 \mathrm{~mm}$

\subsection{Design of coupling}

The basic procedure for finding out the dimensions of the rigid flange coupling consists of the following steps:

(1) Shaft diameter: Calculate the shaft diameter

(2) Dimensions of flanges: Calculate the dimensions of the flange by the following empirical equations:

$$
\begin{aligned}
& \mathrm{d}_{\mathrm{h}}=2 \mathrm{~d} \\
& \mathrm{~L}_{\mathrm{h}}=1.5 \mathrm{~d} \\
& \mathrm{D}=3 \mathrm{~d} \\
& \mathrm{t}=.5 \mathrm{~d} \\
& \mathrm{t}_{1}=.25 \mathrm{~d} \\
& \mathrm{~d}_{\mathrm{r}}=1.5 \mathrm{~d} \\
& \mathrm{D}_{\mathrm{o}}=\left(4 \mathrm{~d}+2 \mathrm{t}_{1}\right)
\end{aligned}
$$

(3) The torsional shear stress in the hub can be calculated by considering it as a hollow shaft subjected to torsional moment $\mathrm{M}_{\mathrm{t}}$.

The inner and outer diameters of the hub are $d$ and $d_{h}$ respectively. The torsional shear stress in the hub is given by,

$$
\begin{aligned}
\mathrm{T} & =\frac{T \times r}{J} \\
\mathrm{~J} & =\prod\left(\mathrm{d}_{\mathrm{h}}{ }^{4}-\mathrm{d}^{4}\right) / 32 \\
\mathrm{R} & =\mathrm{d}_{\mathrm{h}} / 2
\end{aligned}
$$

Shaft diameter $=35 \mathrm{~mm}$

Dimensions of flange are given by following empirical equations:

$$
\begin{aligned}
\mathrm{d}_{\mathrm{h}}=2 \mathrm{~d} & =70 \mathrm{~mm} \\
\mathrm{~L}_{\mathrm{h}}= & 1.5 \mathrm{~d}=52.5 \mathrm{~mm} \\
\mathrm{D} & =3 \mathrm{~d}=105 \mathrm{~mm} \\
\mathrm{t} & =.5 \mathrm{~d}=17.5 \mathrm{~mm} \\
\mathrm{t}_{1} & =.25 \mathrm{~d}=8.75 \mathrm{~mm} \\
\mathrm{~d}_{\mathrm{r}} & =1.5 \mathrm{~d}=52.5 \mathrm{~mm} \\
\mathrm{D}_{\mathrm{o}} & =\left(4 \mathrm{~d}+2 \mathrm{t}_{1}\right)=157.5 \mathrm{~mm} \\
& \text { For } \mathrm{d}<40 \mathrm{~mm}, \mathrm{~N}=3
\end{aligned}
$$

\subsection{Design of hydraulic clampers}

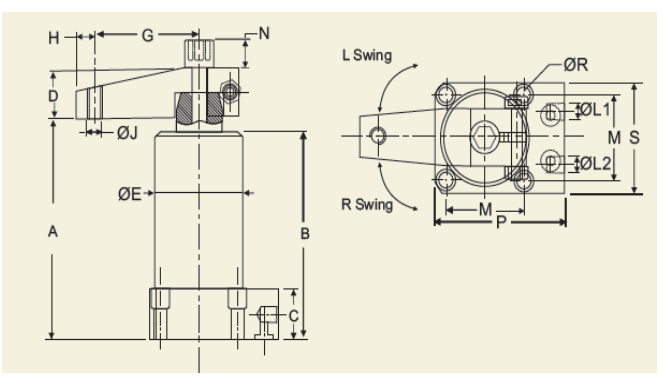

Fig.3 Design of hydraulic clampers 
Table 3 Clamper Specifications

\begin{tabular}{|l|l|l|l|l|l|l|l|l|l|}
\hline Model & $\begin{array}{c}\text { A } \\
\text { unclamp } \\
\text { position }\end{array}$ & B & C & D & E & G & H & J & $\begin{array}{l}\text { INLETS } \\
\text { L1 \&L2 }\end{array}$ \\
\hline $\begin{array}{l}030- \\
92- \\
\text { R L }\end{array}$ & 126 & 102 & 25 & 25 & 47.8 & 45 & 11 & M10 & G1/4 \\
\hline
\end{tabular}

\begin{tabular}{|l|l|l|l|l|l|l|l|l|}
\hline $\mathrm{M}$ & $\mathrm{N}$ & $\mathrm{P}$ & $\mathrm{R}$ & $\mathrm{S}$ & $\begin{array}{l}\text { Bore } \\
\text { dia. }\end{array}$ & $\begin{array}{l}\text { Swing } \\
\text { stroke }\end{array}$ & $\begin{array}{l}\text { Clamping } \\
\text { stroke }\end{array}$ & $\begin{array}{l}\text { Clamping } \\
\text { force(kg) }\end{array}$ \\
\hline 42 & 14.5 & 70.1 & 6.9 & 54 & 32 & 10 & 12 & 550 \\
\hline
\end{tabular}

\section{Actual Model}

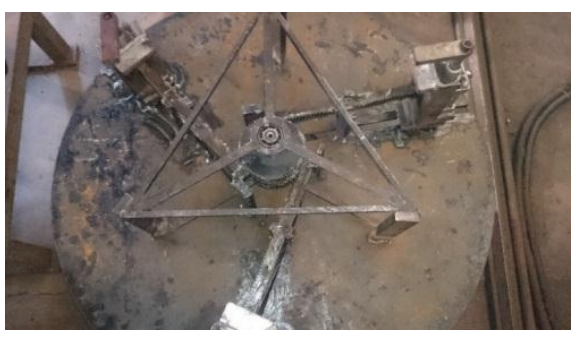

Fig.4 Self-Centering Mechanism without plate

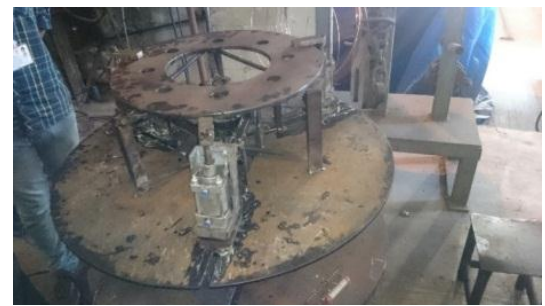

Fig.5 Self-Centering Mechanism with plate

\section{Conclusions}

1) This automation reduced the human effort and hence don't need a person to adjust the plate for drilling.

2) This design also enabled vibration free operation which increased the quality of drill to the plate.

3) It increased the productivity and reduced the cycle time of 1 hour to 15 minutes.

\section{References}

Shailesh S .Pachbhai, Laukik P.Raut (2014) "A Review on Design of Fixtures" International Journal of Engineering Research and General Science Volume 2, Issue 2, Feb-Mar 2014.

T. Papastathisa , 0. Bakkera, S. Ratcheva , A. Popova, Design Methodology for Mechatronic Active Fixtures with Movable Clamps , 45th CIRP Conference on Manufacturing Systems 2012

Chetankumar M. Patel, Dr. G. D. Acharya, Design and manufacturing of 8 cylinder hydraulic fixture for boring yoke on VMC - 1050, 2nd International Conference on Innovations in Automation and Mechatronics Engineering, ICIAME 2014

Atlanta Rack and pinion drive manufacturer's catalogue

Tool Fast Work holding Specification Catalogue 2015 for hydraulic clampers

SKF bearing manufacturer's catalogue

V. B. Bhandari 'Design of Machine Element' Tata McGraw-Hill Education, 2010 - Machine design

Tool Fast Work holding Specification Catalogue 2015 for hydraulic clampers 